\title{
Epigenetic events in medulloblastoma development
}

\author{
Janet C. Lindsey, Ph.D., Jennifer A. Anderton, B.Sc., Meryl E. Lusher, Ph.D., And \\ Steven C. Clifford, Ph.D.
}

\author{
Northern Institute for Cancer Research, University of Newcastle, Newcastle upon Tyne, \\ United Kingdom
}

\begin{abstract}
Over the last decade, the analysis of genetic defects in primary tumors has been central to the identification of molecular events and biological pathways involved in the pathogenesis of medulloblastoma, the most common malignant brain tumor of childhood. Despite this, understanding of the molecular basis of the majority of cases remains poor. In recent years, the emerging field of epigenetics, which describes heritable alterations in gene expression that occur in the absence of DNA sequence changes, has forced a revision of the understanding of the mechanisms of gene disruption in cancer. Accumulating evidence indicates a significant involvement for epigenetic events in medulloblastoma development. Recent studies have identified a series of candidate tumor suppressor genes (for example, RASSF1A, $C A S P 8$, and $H I C 1)$ that are each specifically epigenetically inactivated in a large proportion $(>30 \%)$ of medulloblastomas by promoter hypermethylation, leading to the silencing of their gene expression. These findings shed new light on medulloblastoma and offer great potential for an improved understanding of its molecular pathology. The authors review the current understanding of epigenetic events in cancer and their contribution to medulloblastoma development. Their nature, origins, and functional role(s) in tumorigenesis are considered, and the authors assess the potential utility of these events as a basis for novel diagnostic and therapeutic approaches.
\end{abstract}

\section{KEY WORDS • medulloblastoma • epigenetics • hypermethylation • tumor suppressor gene}

\section{MEDULLOBLASTOMA}

\section{Background and Clinical Challenges}

Medulloblastoma is an invasive embryonal tumor of the cerebellum, and is the most common malignant brain tumor of childhood. ${ }^{25,32}$ Medulloblastomas comprise a group of clinically and histologically heterogeneous neoplasms and, overall, 5-year survival rates of 60 to $70 \%$ are achieved using current risk-adapted combination therapies. At present, the disease risk is defined using clinical disease features alone; however, the outlook for high-risk cases (infants $<3$ years old, patients with metastatic disease at diagnosis) remains particularly poor ( $25-40 \%$ survival $)$, and variability in outcome is observed within each risk group. In addition, the radiotherapeutic components of current treatment strategies are associated with long-term intellectual and neuroendocrine side effects in a significant number of cases..$^{26}$

The accurate identification of clinical risk thus remains a major goal in medulloblastoma, because more robust risk-stratification systems would facilitate the targeted use of adjuvant therapies (intensive regimens for aggressive tumors and reduced long-term side effects for patients with responsive tumors). In addition, the development of more effective therapeutic approaches for high-risk cases remains paramount. A detailed understanding of the molecular mechanisms that contribute to medulloblastoma development, and the relationship of these mechanisms

Abbreviations used in this paper: $\mathrm{PCR}=$ polymerase chain reaction; RLGS = restriction landmark genome scanning; 5 -AzaCdR = 5-Aza-2'-deoxycytidine. to disease biology, pathology, and clinical characteristics therefore offers considerable potential for the identification of more robust markers of disease risk for improved therapeutic stratification. Moreover, a comprehensive functional understanding of how these mechanisms contribute to tumorigenesis could highlight critical molecular targets, against which novel therapeutic strategies could be developed.

\section{Genetic Events in Medulloblastoma Development}

Recent years have witnessed advances in our understanding of the genetic events that underlie medulloblastoma development. Molecular cytogenetic studies have described a number of common chromosomal alterations, including isochromosome $17 \mathrm{q}$, referred to as $\mathrm{i}(17 \mathrm{q})$; gain of chromosome 7; and losses affecting chromosomes 8, 9q, 10q, 11, $16 q$, and $17 p$, either in isolation or as $i(17 q)$, which each occur in more than $25 \%$ of cases. A series of consistently reported genetic aberrations have also been identified, which highlight key biological pathways in medulloblastoma tumorigenesis. These include the following: 1) constitutive activation of the Sonic hedgehog signaling pathway (by mutually exclusive mutations of the PTCH1, SUFU, and $S M O$ genes, which affect $\sim 25 \%$ of cases overall); 2 ) activation of the Wnt/Wingless signaling pathway (by CTNNB1, $A P C$, or AXIN1 mutations, in 10 to $30 \%$ of cases); 3 ) defects in the TP53 tumor suppressor pathway (TP53 mutations, p14 ${ }^{A R F}$ deletions; $~ 20 \%$ of cases); and 4) amplification of the MYC family of oncogenes (MYC or MYCN, each in 5$15 \%$ of cases). Furthermore, functional modeling and clini- 


\section{A. Transcriptionally active chromatin}
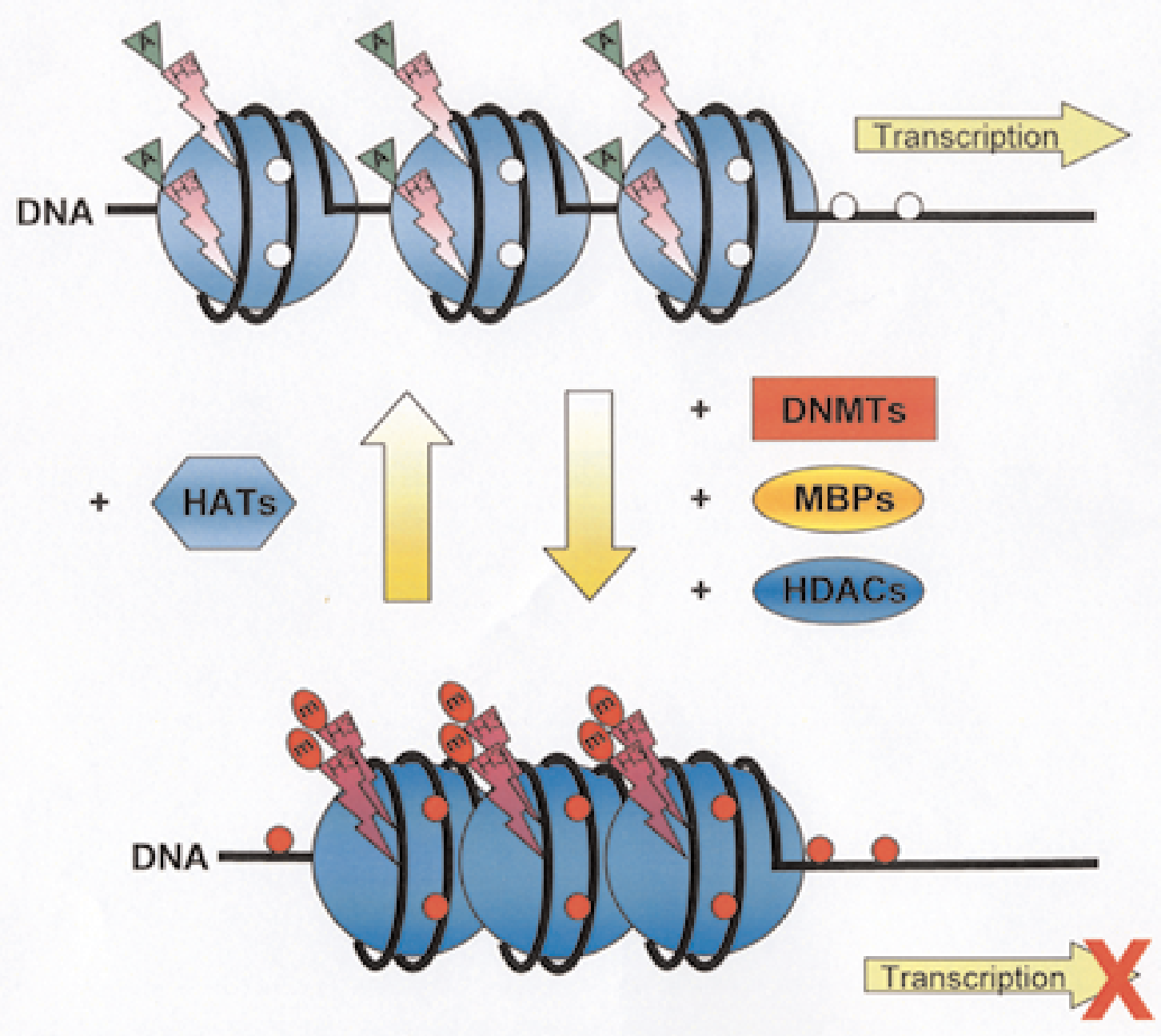

\section{B. Transcriptionally inactive chromatin}

Fig. 1. Schematic drawings showing epigenetic control of gene transcription by alterations in DNA methylation status and chromatin modifications. A: Transcriptionally active DNA has an open chromatin structure with widely spaced nucleosomes (light blue circles). This is associated with unmethylated $\mathrm{CpG}$ residues on the DNA (white circles) and specific posttranslational histone modifications, including increased levels of acetylation (green triangles) of key histone $\mathrm{H} 3$ lysine residues (light pink arrows). The resultant DNA is readily accessible to histone acetyl transferases (HATs) as well as other enzymes and cofactors important in gene transcription. B: Chromatin may be transformed into a transcriptionally repressive conformation, which is characterized by methylated CpGs on the DNA (red circles), compacted nucleosomes (dark blue circles), with deacetylated histones (dark pink arrows), and further posttranslational modifications, including methylation of specific histone $\mathrm{H} 3$ lysine residues (red ovals). This repressive conformation renders the DNA inaccessible to the transcriptional machinery, and is established and maintained by proteins, including methyl-CpG binding proteins (MBPs), histone deacetylases (HDACs), and DNA methyltransferases (DNMTs).

cal analysis of these genetic defects both substantiate their role(s) in medulloblastoma tumorigenesis and suggest that their differential involvement may indicate divergent mechanisms of pathogenesis and clinical behavior. ${ }^{25-28,50,81}$

\section{Identifying Further Molecular Events in Medulloblastoma Development: an Emerging Role for Epigenetic Mechanisms?}

Despite recent progress, a genetic basis for the majority of medulloblastomas remains to be discovered; genetic de- fects identified to date only describe limited subsets of medulloblastomas, and specific target genes have not been identified for the majority of chromosomal defects observed. Moreover, emerging evidence suggests that the disruption of specific genes in tumor development can occur by alternative mechanisms to genetic events (for example, gene mutation or deletion). In particular, the epigenetic inactivation of tumor suppressor genes by promoter hypermethylation has become the focus of intense investigation in multiple tumor types. Studies conducted over the last 5 years have begun to define the epigenetic events in- 
volved in medulloblastoma. These investigations have led to the identification of common gene-specific events that can occur either independently or in conjunction with genetic defects to disrupt genes involved in disease pathogenesis. We review our current understanding of the contribution of these events to medulloblastoma. We consider the nature of these events and the experimental strategies that have been undertaken to establish their role(s) in disease pathogenesis. Finally, we discuss their potential for diagnostic, prognostic, and therapeutic application in this disease.

\section{Methylation of DNA and Epigenetic Transcriptional Silencing}

Epigenetic events can be defined as those that effect heritable changes in gene expression without a change in the DNA sequence. In mammals, the best understood epigenetic modification of DNA is postreplicative methylation of the $\mathrm{C} 5$ position of cytosine residues in $\mathrm{CpG}$ dinucleotides. This is intimately related to a series of posttranslational epigenetic modifications of histones, and together these two mechanisms interact to cause the remodeling of chromatin into a transcriptionally repressive structure, which affects changes in gene expression by altering the accessibility of DNA to the cell's transcriptional machinery (Fig. 1)., ${ }^{9,23}$ The human genome is generally depleted in the dinucleotide $\mathrm{CpG}$; however, approximately $60 \%$ of genes contain $\mathrm{CpG}$ islands, regions of DNA with a high $\mathrm{G}+\mathrm{C}$ content and a high frequency of $\mathrm{CpG}$ dinucleotides relative to the bulk genome (Fig. 2). ${ }^{2,31}$ These $\mathrm{CpG}$ islands are usually located near upstream promoter regions and/or transcriptional start sites of genes. ${ }^{39}$ In normal adult somatic cells these promoter-associated $\mathrm{CpG}$ islands are generally unmethylated and their associated genes are transcriptionally active (exceptions are discussed later in this review), whereas the majority of $\mathrm{CpG}$ dinucleotides elsewhere in the genome (for example, in parasitic and repetitive DNA elements) are generally methylated. ${ }^{7}$ Briefly, DNA methylation patterns are established and maintained by a family of DNA methyltransferases, and their interplay with histone modifications and chromatin remodeling througha cascade of proteins, including methyl-CpG binding proteins, histone acetylases, and acetyltransferases (Fig.1). Mechanisms underlying the establishment and maintenance of DNA methylation patterns, histone modifications, and transcriptional repression have been reviewed in detail elsewhere. ${ }^{45}$

\section{Epigenetic Events and Human Disease}

The establishment and maintenance of appropriate DNA methylation patterns is essential in normal mammalian development and function, and plays a critical role in the regulation of a range of normal cellular processes, including embryonic growth and development, $\mathrm{X}$ chromosome inactivation, and genomic imprinting. ${ }^{70}$ Methylation of DNA has also been proposed as an important mechanism in the regulation of genomic stability, including the silencing of retroviruses and transposable elements in the genome, ${ }^{91}$ and plays a role in the regulation of tissue-specific patterns of transcription. ${ }^{9}$ In line with such fundamental biological roles, aberrations in DNA methylation patterns and processes have been associated with a range of human dis- eases, including imprinting disorders. Examples include: Beckwith-Wiedemann, Prader-Willi, and Angelman syndromes, repeat-instability diseases (such as fragile $\mathrm{X}$ syndrome), and cancer. ${ }^{70}$

\section{Epigenetic Events in Tumor Development}

A large body of evidence now implicates a major role for epigenetic mechanisms in cancer development. ${ }^{6,45,46}$ Patterns of DNA methylation become disrupted in cancer at two major levels. 1) The genome of the cancer cell generally becomes hypomethylated relative to normal cells, contributing to the genomic instability frequently observed in malignancy. ${ }^{24}$ 2) Hypermethylation events arise that affect specific genes and lead to their epigenetic inactivation, and hence play more specific functional roles in cancer pathogenesis. ${ }^{45}$ These represent the most widely investigated epigenetic events in cancer, and typically occur somatically at $\mathrm{CpG}$ islands, which are normally unmethylated, resulting in an altered chromatin structure and transcriptional silencing (as described earlier; Fig. 1).

Hypermethylation is critically involved in the epigenetic inactivation of tumor suppressor genes, which normally function to suppress the neoplastic phenotype. The list of tumor suppressor genes silenced by hypermethylation has been steadily growing. The first example reported was of hypermethylation of the $R B 1$ gene in sporadic retinoblastomas, in 1993; ${ }^{60}$ today the M. D. Anderson Cancer Center at the University of Texas maintains a database (http:// www.mdanderson.org/departments/methylation), in which are listed more than 60 genes that have been reported to be hypermethylated in human cancers (although it is noteworthy that this list is not fully comprehensive, and more genes continue to be described).

Aberrant DNA hypermethylation events affecting tumor suppressor genes have been described for most tumor types, and characterize genes involved across the spectrum of tumor development processes, including cell cycle control, metastasis, angiogenesis, apoptosis, cell signaling, and DNA repair. Importantly, hypermethylation events can occur either biallelically (that is, affecting both alleles), or in conjunction with genetic events (for example, mutation or deletion), to deliver the two hits necessary to inactivate both copies of a tumor suppressor gene, and thus promote tumor development. ${ }^{44-46,48}$

The initiating events that cause somatic methylation of $\mathrm{CpG}$ islands in cancers are not fully understood. Recent studies have proposed that de novo methylation can initiate from normally methylated $\mathrm{CpG}$ residues at the peripheries of a $\mathrm{CpG}$ island, or as "seeds" of methylation affecting individual $\mathrm{CpG}$ sites within an island, which then spread to encompass the entire $\mathrm{CpG}$ island, accompanied by associated histone modifications, transcriptional silencing, a growth advantage, and subsequent clonal selection.77,85 Gene-specific hypomethylation events, which lead to increased gene expression, have also been reported in cancer and are discussed in later sections.

\section{Identification of Hypermethylated Genes in Medulloblastoma}

Initial clues that patterns of DNA methylation are disrupted at the whole-genome level during medulloblasto- 


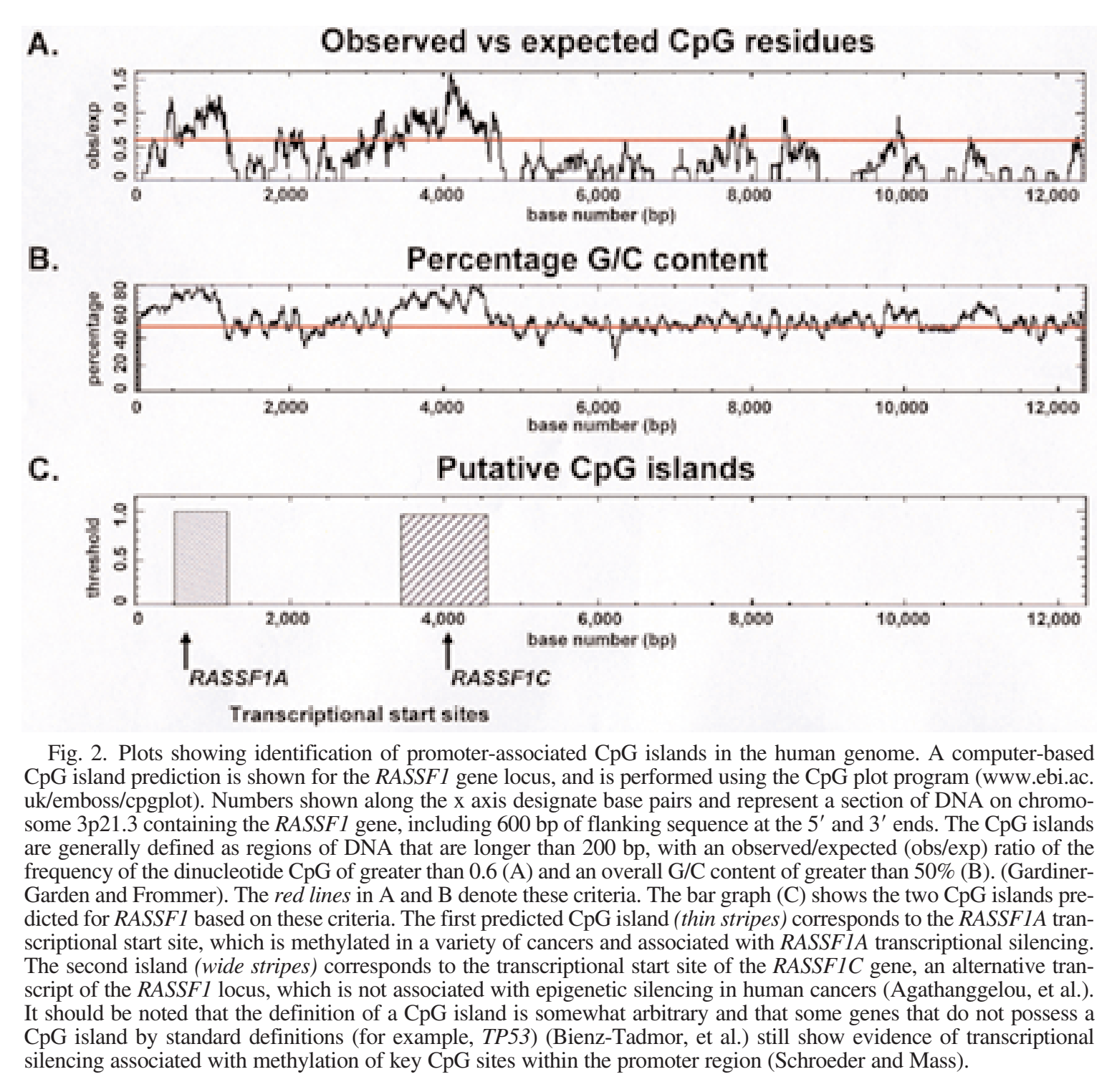

ma pathogenesis were provided by studies in which methylation-sensitive restriction enzymes and two-dimensional gel electrophoresis (called RLGS) were used. Restriction enzymes recognize and cut defined nucleotide sequences within the genome. A subset of these enzymes is inhibited by methylation of a $\mathrm{CpG}$ residue within their recognition sites and thus allows the distinction of methylated and unmethylated $\mathrm{CpG}$ residues within a $\mathrm{CpG}$ island. In RLGS, digestion of total genomic DNA with a combination of methylation-sensitive and other restriction enzymes, followed by two-dimensional gel electrophoresis, produces an electropherogram that displays approximately 2500 different sequences containing $\mathrm{CpG}$ residues. The pattern of these spots can be compared between medulloblastoma and normal cerebellar tissue, providing an insight into the methylation changes occurring at the global level. This analysis has led researchers to propose that up to $6 \%$ of $\mathrm{CpG}$ islands showed evidence of an altered methylation status in medulloblastoma. ${ }^{14,29}$
Researchers have proceeded to look for specific genes affected by DNA methylation in medulloblastoma. To date, the majority of genes analyzed have been assessed for evidence of epigenetic inactivation on a "candidate" gene basis. Individual genes have been selected for analysis either because they are known to be inactivated by genetic mechanisms in medulloblastoma, or because they are genes that show evidence of epigenetic inactivation in other cancers.

Alterations in DNA Methylation in Medulloblastoma Tumors and Cell Lines. At least 16 published studies have now analyzed 24 genes for evidence of $\mathrm{CpG}$ island methylation in medulloblastoma. $22,29,33,34,36,37,40,53-55,62,68,71,72,88,93$ The methods used for the detection of DNA methylation in these tumors are illustrated and reviewed in Fig. 3, and their key features are summarized in Table 1 . Of the 24 genes analyzed, 16 have shown evidence of $\mathrm{CpG}$ island methylation in a percentage of primary medulloblastomas in at least one study (p16 INKAA,$p 14^{A R F}$, TP73, TP53, RB1, RASSF1A, HIC1, EDNRB, CASP8, DAPK, CDH1, THBS1, TIMP3, GSTP1, 


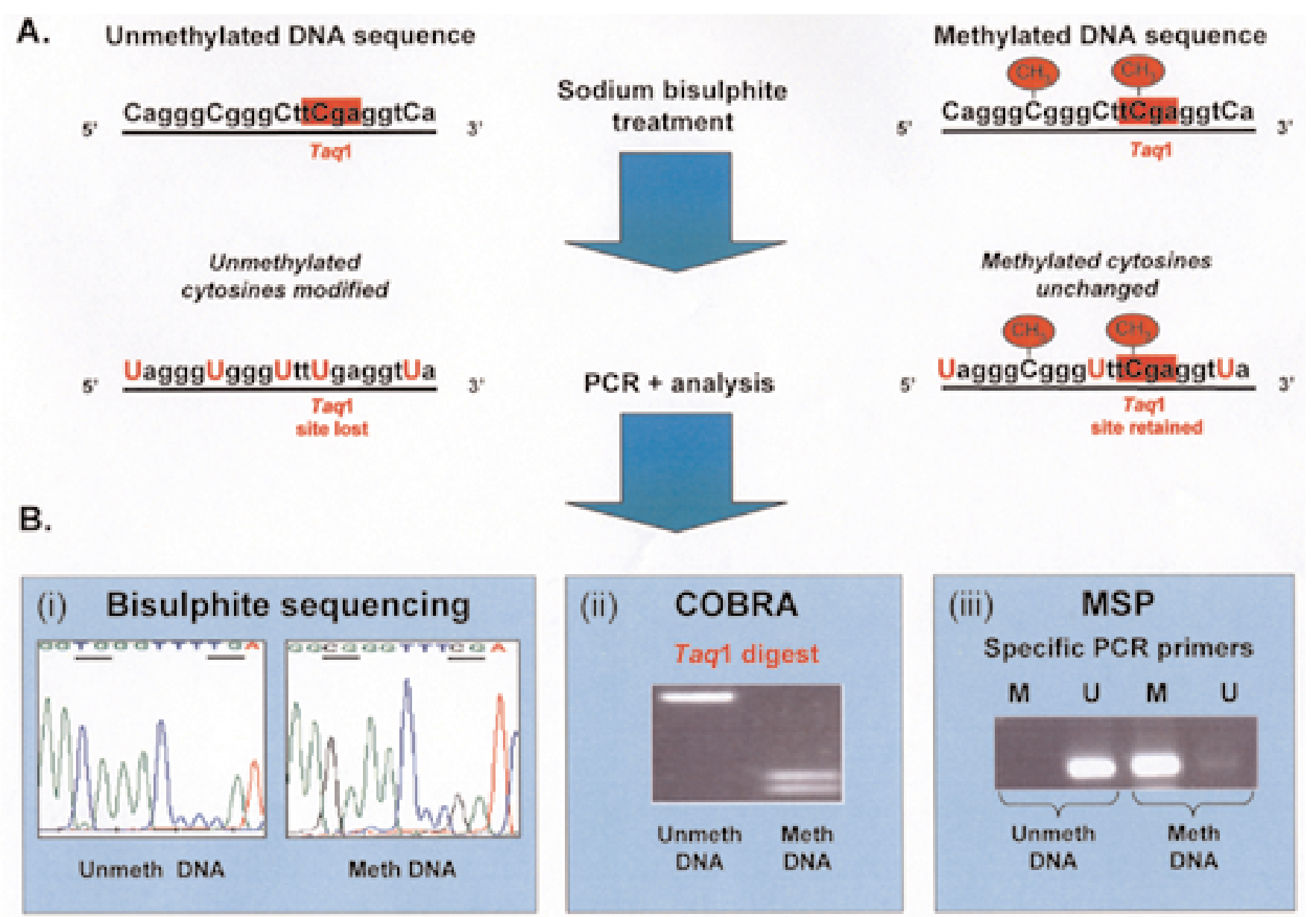

Fig. 3. Schema showing methods used for the assessment of DNA methylation status in medulloblastoma. A: Sodium bisulfite modification of DNA forms the basis of most commonly used epigenetic analysis methods. Treatment of single-stranded DNA with sodium bisulfite selectively deaminates cytosine residues (C), converting them to uracils (U), whereas methylcytosine residues $(\mathrm{CH} 3)$ remain unaffected. B: The modified DNA sequence can then be analyzed for evidence of sequence variations by using a range of PCR amplification-based methods. The most widely used techniques include those depicted in panels i, ii, and iii. In bisulfite DNA sequencing (i), converted DNA is amplified using PCR with the aid of primers that do not differentiate between methylated and unmethylated sequences. The PCR products are then either sequenced directly or ligated into a plasmid vector for cloning and subsequent sequencing. Only methylated cytosine residues are retained as cytosines in the resulting sequence, whereas unmethylated cytosines are converted to uracils and appear as thymidine residues (T). In combined bisulfite restriction analysis (COBRA [ii]), DNA is amplified using PCR as per (i), and is then subjected to digestion by using sequence-specific restriction enzymes whose DNA recognition site(s) contain $\mathrm{CpG}$ residues. In the example shown, the TCGA recognition site of restriction enzyme Taql is retained in the methylated (unaltered) DNA sequence (Meth DNA) but is lost in the unmethylated DNA sequence (Unmeth DNA) as a result of the bisulfite treatment. The Taq1-digested PCR products are then resolved by agarose gel electrophoresis. In methylation-specific PCR (MSP [iii]), the primers used specifically recognize and amplify either methylated $(\mathrm{M})$ or unmethylated (U) target DNA sequences. The DNA is amplified in parallel with the two primer sets and the PCR products are then analyzed using agarose gel electrophoresis.

$M G M T$, and $M C J)$. These data are summarized in Table 2. The RASSF1A, CASP8, and HICl genes consistently show methylation in a high percentage $(>60 \%)$ of cases, whereas the frequency of methylation is lower for the remaining genes $(<20 \%$ of cases, when averaged between studies). Frequencies of methylation show variation between individual studies. This is a likely consequence of two key factors; first, small cohorts were analyzed in many studies (that is, $<20$ primary tumors), and second, different methods were used, which can influence rates of detection (Table 1). In particular, methylation-specific PCR, one of the most commonly used methods of detection, can exhibit variable detection rates depending on the precise experimental conditions used..$^{17}$ Despite this, consistent evidence of methylation has been found for four of the genes (RASSF1A, CASP8, HICl, and $p 16^{I N K 4 A}$ ), which have been analyzed using multiple methods across three or more independent studies, thus providing strong corroborative evidence for their methylation in medulloblastoma. Four additional genes (MGMT, CDH1, TIMP3, and GSTP1) have exhibited consistent evidence of hypermethylation in two independent studies. The remaining genes have been the 
TABLE 1

Advantages and disadvantages of DNA methylation detection techniques used in medulloblastoma*

\begin{tabular}{|c|c|c|}
\hline Technique & Advantages & Disadvantages \\
\hline $\begin{array}{l}\text { BS: high-resolution mapping of methylation status } \\
\text { across large stretches }(\sim 100-500 \mathrm{bp}) \text { of bi- } \\
\text { sulphite-converted DNA }\end{array}$ & $\begin{array}{l}\text { semiquantitative, allows analysis of } \\
\text { long stretches of sequence contain- } \\
\text { ing multiple } \mathrm{CpG} \text { residues }\end{array}$ & time consuming \& relatively expensive \\
\hline $\begin{array}{l}\text { MSP: PCR reactions designed specifically to } \\
\text { amplify either methylated or unmethylated } \\
\text { DNA after bisulphite conversion }\end{array}$ & rapid \& highly sensitive & $\begin{array}{l}\text { detection highly dependent on assay conditions, not quan- } \\
\text { titative, assesses methylation status of only a few } \\
\text { CpG residues, cannot determine differences in methyla- } \\
\text { tion btwn different CpGs contained in primer recogni- } \\
\text { tion sequences }\end{array}$ \\
\hline $\begin{array}{l}\text { COBRA: PCR products from bisulphite-treated } \\
\text { DNA are digested w/ a restriction enzyme } \\
\text { specific to methylated or unmethylated DNA } \\
\text { sequences }\end{array}$ & quantitative, relatively straightforward & $\begin{array}{l}\text { only assesses methylation status of } \mathrm{CpG} \text { residues at spe- } \\
\text { cific DNA restriction sites, therefore usually only } \\
\text { assesses a limited number of } \mathrm{CpG} \text { residues }\end{array}$ \\
\hline $\begin{array}{l}\text { MSRA: digestion of genomic DNA w/ methyla- } \\
\text { tion-sensitive restriction enzymes followed by } \\
\text { detection w/ Southern blot or PCR amplification }\end{array}$ & $\begin{array}{l}\text { avoids bisulphite treatment, can be } \\
\text { quantitative }\end{array}$ & $\begin{array}{l}\text { requires large amounts of DNA, lengthy procedure, only } \\
\text { assesses methylation status of } \mathrm{CpG} \text { residues at specific } \\
\text { DNA restriction sites }\end{array}$ \\
\hline
\end{tabular}

* $\mathrm{BS}=$ bisulfite DNA sequencing; COBRA = combined bisulfite and restriction analysis; MSP = methylation-sensitive PCR; MSRA = methylation-sensitive restriction analysis.

subject of only one study to date, or have been investigated in two studies with conflicting findings.

Cell lines provide useful model systems for the investigation of DNA methylation events in cancer, particularly in terms of investigating the relationship between methylation events and transcriptional silencing in vitro (see later sections). The majority of studies of medulloblastoma have investigated the methylation status of medulloblastoma cell lines alongside primary tumors (Table 2). Based on the data reported in these studies, cell lines provide useful indicators of methylation in medulloblastoma; the majority of genes identified as methylated in primary tumors are also methylated in cell lines. Nevertheless, limitations do exist in the analysis of methylation events in cell lines, and these are critical to their appropriate interpretation. Medulloblastoma cell lines typically show higher frequencies of $\mathrm{CpG}$ island methylation than primary tumors (Table 2). Indeed, there is evidence that continuous cultivation of immortalized cells can be associated with the acquisition of specific DNA methylation events that are unrelated to the tumor of origin. ${ }^{47,63}$ Furthermore, genetic evidence indicates that medulloblastoma cell lines are generally derived from more aggressive tumors and do not represent the full spectrum of disease subtypes observed clinically. ${ }^{51}$ It is therefore critical that, in addition to cell lines, methylation events are assessed in representative tumor cohorts to determine accurately the extent of their involvement in the clinical disease.

Establishing Tumor Specificity: Origins of DNA Methylation in Medulloblastoma. Although promoter-associated $\mathrm{CpG}$ islands are usually unmethylated in adult tissues, ${ }^{9}$ significant precedents exist for genes that are transcriptionally silenced by DNA methylation in normal tissues. ${ }^{79}$ These include genes silenced by imprinting (a developmental mechanism that regulates gene dosage), and results in the expression of a gene from only one of the two parental chromosomes, with the other copy silenced by DNA methylation. More than 80 imprinted genes have been described to date in the human genome. ${ }^{5,38}$ Similarly, a set of testisspecific genes exist (for example, members of the $M A G E$ [melanoma-associated antigen] and GAGE [G-antigen] gene families) that are epigenetically silenced by methylation in all somatic tissues.92

Several genes have also been described that exhibit tissue-specific, methylation-controlled expression (that is, they are methylated and silenced in some somatic tissue types and not others). Examples include SERPINB5, MCJ (DNAJD1), and $T H .3,30,78$ The transcriptional inactivity of one copy of the $\mathrm{X}$ chromosome in females (X inactivation) is associated with widespread methylation of the $\mathrm{CpG}$ islands of its genes. ${ }^{38}$ Finally, evidence has been reported that supports the acquisition of methylation of certain genes in somatic tissues in an age-dependent manner. ${ }^{69}$ Considering these precedents, it is important to establish the relationship between any patterns of methylation detected in tumors and those observed in the normal tissue from which they have arisen, and also whether they represent tumor-specific events. Such investigations should ideally be performed using matched normal control tissues that are developmentally and histologically relevant to the tumor type of interest. Nevertheless, the selection of appropriate controls for medulloblastoma tumors poses particular problems. Although strong evidence supports the development of a subset of medulloblastomas that contain defects in the Sonic hedgehog signaling pathway, from the external granular layer of the developing cerebellum $(<30 \%)$, the histogenesis of the majority of medulloblastomas, and hence their most relevant control cell populations, are less well defined. ${ }^{26,81}$

Studies of medulloblastoma to date have typically used a variety of normal postmortem brain tissues from unrelated individuals as controls for these purposes; however, only a subset of these have included normal nonneoplastic cerebellar tissues representing a range of ages and developmental stages (Table 2). From these studies, three genes that are methylated in medulloblastomas also show evidence of methylation in nonneoplastic brain tissues; these are CASP8, HICl, and EDNRB. The patterns of methylation observed for these genes are markedly different. Methylation observed for $E D N R B$ is partial, and is present at similar levels and frequencies in tumor and nonneoplas- 
TABLE 2

Summary of gene-specific methylation studies in medulloblastoma*

\begin{tabular}{|c|c|c|c|c|c|c|}
\hline \multirow[b]{2}{*}{ Gene } & \multicolumn{3}{|c|}{ Methylation Frequency (\%) } & \multirow[b]{2}{*}{ Method } & \multirow[b]{2}{*}{$\begin{array}{l}\text { Assoc w/ } \\
\text { Silencing }\end{array}$} & \multirow[b]{2}{*}{ Ref } \\
\hline & MB Cell Lines & Primary MBs $\dagger$ & $\begin{array}{l}\text { Nonneo Brain } \\
\text { Samples }\end{array}$ & & & \\
\hline \multirow[t]{5}{*}{ CASP8 } & 4 of $5(80)$ & 36 of $40(90)$ & & MSP & & 22 \\
\hline & & 15 of $24(62)$ & & MSP & & 33 \\
\hline & 2 of $3(67)$ & 13 of $16(81)$ & & BS/MSP & yes & 37 \\
\hline & 8 of 11 (73) & 38 of $39(97)[36]$ & 5 of $5(100) \S$ & COBRA/MSP & yes: & 53 \\
\hline & 4 of 7 (57)॥ & 11 of $11(100) \|$ & & MSP & yes** & 93 \\
\hline \multirow[t]{5}{*}{ pl6 $6^{I N K 4 A}$} & 2 of $5(40)$ & 1 of $46(2)$ & & MSP & & 22 \\
\hline & 3 of $5(60)$ & 3 of $20(15)$ & 0 of $5(0) \S$ & BS/MSP & yes & 29 \\
\hline & & 7 of $11(64)$ & 0 of $5(0)$ & MSP & & 34 \\
\hline & 0 of $3(0)$ & 0 of $16(0)$ & & MSP & & 36 \\
\hline & 1 of 11 (9) & 3 of 44 (7) & 0 of $5(0) \S$ & MSP & & 53 \\
\hline \multirow[t]{4}{*}{$\mathrm{HICl}$} & 11 of $11(100)$ & 43 of $44(98)[39]$ & 5 of $5(100) \S$ & MSP & yes & 53 \\
\hline & 1 of $1(100)$ & 12 of $15(80)$ & & MSP & yesf & 68 \\
\hline & & 23 of $36(72)[64]$ & 11 of $12(92) \S$ & MSRA & & 72 \\
\hline & 7 of 8 (88) & 33 of $39(85)$ & 0 of $5(0) \S$ & BS/MSP/MSRA & yes & 88 \\
\hline \multirow[t]{4}{*}{$M G M T$} & 1 of $5(20)$ & 0 of $44(0)$ & & MSP & & 22 \\
\hline & & 2 of $11(18)$ & 0 of $2(0)$ & MSP & & 34 \\
\hline & 0 of $3(0)$ & 0 of $16(0)$ & & MSP & & 37 \\
\hline & & 28 of 37 (76) & & MSP & & 71 \\
\hline \multirow[t]{4}{*}{ RASSF $1 A$} & 2 of 3 (67) & 14 of $16(88)$ & & MSP & & 36 \\
\hline & & 5 of $5(100)$ & & MSP & & 40 \\
\hline & 11 of $11(100)$ & 41 of $44(93)$ & 0 of $5(0) \S$ & BS & yesł & 53 \\
\hline & 8 of $8(100)$ & 27 of 34 (79) & 1 of $9(11) \S$ & BS/COBRA & yes & 55 \\
\hline \multirow[t]{3}{*}{$\mathrm{CDH} 1$} & 1 of $4(25)$ & 3 of $36(8)$ & & MSP & & 22 \\
\hline & 3 of $5(60)$ & 4 of $20(20)$ & 0 of $5(0) \S$ & MSP & & 29 \\
\hline & 1 of $3(33)$ & 0 of $16(0)$ & & MSP & & 36 \\
\hline \multirow{3}{*}{ TIMP-3 } & 1 of $5(20)$ & 1 of 38 (3) & & MSP & & 22 \\
\hline & & 1 of $11(9)$ & 0 of $2(0)$ & MSP & & 34 \\
\hline & 0 of $11(0)$ & & & MSP & & 53 \\
\hline \multirow{2}{*}{$D A P K$} & & 4 of $11(36)$ & 0 of $2(0)$ & MSP & & 34 \\
\hline & 0 of $3(0)$ & 0 of $16(0)$ & & MSP & & 36 \\
\hline \multirow[t]{2}{*}{ GSTP1 } & & 2 of $11(18)$ & 0 of $2(0)$ & MSP & & 34 \\
\hline & 0 of $3(0)$ & 1 of $16(6)$ & & MSP & & 36 \\
\hline \multirow{2}{*}{ p14 } & & 5 of $11(45)$ & 0 of $2(0)$ & MSP & & 34 \\
\hline & 4 of $11(36)$ & 2 of $44(5)$ & 0 of $5(0) \ddagger$ & MSP & & 53 \\
\hline \multirow[t]{2}{*}{ TP53 } & & 0 of $20(0)$ & & MSP & & 29 \\
\hline & & 1 of 11 (9) & 0 of $2(0)$ & MSP & & 34 \\
\hline \multirow[t]{2}{*}{$T P 73$} & & 2 of $11(18)$ & 0 of $2(0)$ & MSP & & 34 \\
\hline & 0 of $11(0)$ & & & BS & & 53 \\
\hline EDNRB & 9 of $11(82)$ & 26 of $44(59)$ & 3 of $5(60) \S$ & MSP & & 53 \\
\hline$M C J$ & 3 of 9 (33) & 2 of $28(7)$ & 0 of $11(0) \S$ & BS/COBRA & yest & 54 \\
\hline$R B 1$ & & 1 of 11 (9) & 0 of $2(0)$ & MSP & & 34 \\
\hline THBS1 & & 3 of 11 (27) & 0 of $2(0)$ & MSP & & 34 \\
\hline
\end{tabular}

* Additional genes analyzed and found to be unmethylated in medulloblastoma include $A P C$ (0/16 tumors), $C D H 1$ ( $0 / 16$ tumors), DLC-1 (0/21 tumors), $p 15^{I N K 4 B}$ (0/11 medulloblastoma cell lines and 0/20 tumors), RAR $\beta$ (0/16 tumors), RIZ1 (0/44 tumors), TSLC1 (0/11 medulloblastoma cell lines), and $V H L(0 / 20$ medulloblastomas). (See references 36 [for APC, CDH1, and RAR $\beta$ genes], 62 [DLC1], $29\left[p 15^{I N K 4 B}\right.$ and $\left.V H L\right]$, and $53\left[p 15^{I N K 4 B}, R I Z 1\right.$, and TSLC1]). Abbreviations: assoc = association; MB = medulloblastoma; Nonneo = nonneoplastic PNET = primitive neuroectodermal tumor; Ref $=$ reference .

$\dagger$ Brackets denote methylation more intense than normal brain in the percentage of cases indicated.

\$ Transcriptional silencing and gene reactivation after 5-AzaCdR treatment in cell lines.

$\S$ Includes cerebellar tissue.

॥ Cohort included supratentorial PNET samples.

** Expression levels correlate with methylation status in cell lines.

$\dagger \dagger$ Expression correlates with methylation status in primary tumors.

tic cerebellar tissues, indicating that it is probably reflective of a normal level of tissue-specific methylation, and not a tumor-related event. ${ }^{53}$ Methylation patterns observed for CASP8 and HICl, however, are more complex. For both genes, a background level of partial methylation is observed in normal brain and cerebellar biopsy samples, with higher levels of methylation observed in a proportion of medulloblastomas, which is indicative of an enhanced tumor-related methylation state..$^{53}$

The remaining medulloblastoma-methylated genes that have been investigated in control tissues fall into two broad groups. First, RASSF $1 A$ is frequently completely methylated in primary medulloblastomas but shows no evidence of methylation in a range of nonneoplastic cerebellar biopsy samples, indicating that its methylation is tumor specific. Second, there is a group of genes that displays lower frequencies of methylation in primary tumors (typically $<$ 20\%; p144RF, p16 INK4A, MGMT, CDH1, TIMP-3, DAPK, GSTP1, TP53, TP73, RB1, and THBS1). Although these genes were unmethylated when examined in limited numbers of control tissues, investigations have not been sufficiently extensive (in number or tissue type) to indicate 


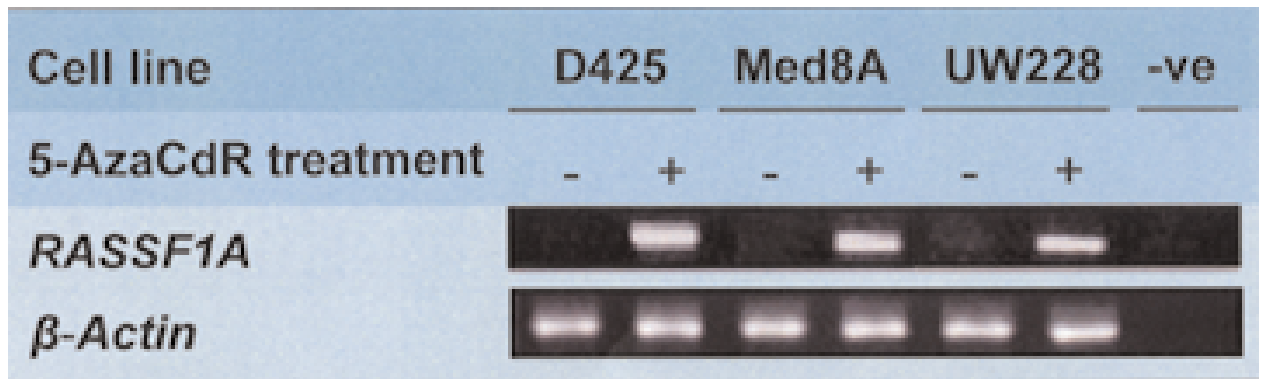

Fig. 4. Reversal of methylation-dependent transcriptional silencing of RASSF1A in medulloblastoma cell lines by 5-AzaCdR treatment. Three medulloblastoma cell lines that display RASSF1A promoter hypermethylation (D425, Med8A, and UW228) were grown in normal culture medium in the presence $(+)$ or absence $(-)$ of the demethylation agent 5-AzaCdR (5 $\mu \mathrm{M}$ for 72 hours). Cells were harvested and RNA extracted and then reverse-transcribed to complementary DNA, which was used as substrate DNA for PCR analysis. The PCR products generated using primers specific for the RASSF1A (test gene) or $\beta$-Actin (housekeeping control gene) transcripts are shown. The RASSF1A gene transcripts are absent from untreated cell lines but abundantly present in treated cells, which is indicative of methylationdependent transcriptional silencing. Expression levels of the $\beta$-Actin control transcript remain constant.

whether their methylation in medulloblastoma is tumor specific.

These studies together identify three genes (RASSF1A, $H I C l$, and CASP8) that show evidence of differential methylation between medulloblastoma tumors and control cerebellar tissues, which is indicative of tumor-specific hypermethylation. Furthermore, the identification of normal tissue-specific methylation events in the nonneoplastic cerebellum highlights the importance of including relevant somatic tissue controls in medulloblastoma methylation studies. Age-matched normal cerebellar material currently represents the best available human control for such experiments; however, the origins of the apparent tumor-specific methylation observed in medulloblastomas remain elusive. Although functional evidence is accumulating to support bona fide tumor suppressor roles for these genes, and hence a direct role for their methylation in tumorigenesis (see later sections), the mechanisms underlying de novo methylation in tumor development are unclear (see earlier sections). The possibility also remains that the methylation patterns observed in medulloblastomas could reflect their histogenesis and clonal expansion from specific subpopulations of cells in the normal or developing cerebellum, and any cell-specific methylation patterns contained therein. Specific patterns of global DNA methylation and demethylation have also been described in early embryogenesis, which may relate to patterns of methylation observed in tumors. ${ }^{56}$ Clearly, further investigations in primary tumors and developing tissues in both humans and model organisms are now required to determine the relationships between normal methylation events in cerebellar development, de novo methylation events, and their roles in tumor histogenesis and establishment of the methylation patterns observed in medulloblastomas.

Establishing Epigenetic Inactivation: Relationships to Transcriptional Silencing. Once evidence of DNA methylation has been established for a given gene in cell lines and tumors, it is important next to determine whether this methylation leads to epigenetic inactivation (that is, transcriptional silencing) of the corresponding gene transcript. This is not always the case; methylation of certain $\mathrm{CpG}$ islands downstream from the promoter in mammalian genes have been shown not to block transcription. ${ }^{44}$ Correlation of the messenger RNA levels in cell lines and primary tumors with the presence/absence of methylation provides evidence for epigenetic inactivation; however, such an approach is often difficult in primary tumors because the presence of contaminating normal tissues may obscure the results. More direct evidence comes from the treatment of cultured cell lines with demethylating agents such as 5-AzaCdR, a nucleotide analog that inhibits cytosine methylation, causing reactivation of genes transcriptionally silenced by DNA methylation. ${ }^{43}$ Ideally, messenger RNA transcripts should be absent before treatment in cell lines in which there is evidence of DNA methylation (that is, lines showing evidence of transcriptional silencing) and be restored following treatment, with such a result providing strong evidence that any observed transcriptional silencing is methylation dependent. An illustrative example of such an analysis is shown in Fig. 4.

For RASSF1A, HICl, and CASP8, consistent evidence of a relationship between DNA methylation and epigenetic inactivation has been observed across multiple studies in medulloblastoma. Additionally, similar relationships have been reported for $p 16^{I N K 4 A}$ and $M C J$ in medulloblastoma in individual studies (see Table 2 and the studies cited therein). Nevertheless, the remaining studies of other genes in medulloblastoma have reported $\mathrm{CpG}$ island methylation without establishing its relationship to transcriptional silencing in medulloblastomas or cell lines (Table 2), although equivalent relationships have been reported for many of these genes in other tumor types. A number of assays of alternative markers of epigenetic inactivation are also available (for example, chromatin immunoprecipitation assays for evidence of DNA methylation-associated histone modification and chromatin remodeling), ${ }^{76}$ although these have not been used yet in reported studies of DNA methylation in medulloblastoma.

Summary. The assessment of candidate tumor suppressor genes for evidence of promoter hypermethylation has demonstrated that epigenetic events are a significant feature of medulloblastoma development, and has highlighted a series of genes that are epigenetically inactivated in medulloblastomas. Most notably, epigenetic inactivation of 
RASSF1A, HIC1, and CASP8 represent the most prevalent gene-specific events described in medulloblastoma to date. Each gene shows strong and consistent evidence of tumorrelated $\mathrm{CpG}$ island hypermethylation in a significant proportion $(>30 \%)$ of medulloblastomas, across several independent studies using a range of methodologies, which is associated with their epigenetic inactivation by transcriptional silencing. In studies in which quantitative methylation detection methods have been used, the complete methylation observed for RASSFIA in the majority of primary medulloblastomas is consistent with a role as an early event in tumorigenesis. ${ }^{53,55}$ For most other genes, however, analysis has been restricted to a preliminary examination of methylation by methylation-specific PCR in small tumor cohorts in single studies. From the accumulated data, promoter-associated $\mathrm{CpG}$ island methylation in medulloblastoma appears to be restricted to specific genes, and medulloblastomas do not show evidence of concordant methylation of multiple genes, the so-called $\mathrm{CpG}$ island methylator phenotype reported in colorectal carcinomas and some other cancers. ${ }^{86}$

\section{Epigenetically Inactivated Genes in Medulloblastoma: Evidence for Roles in Tumorigenesis}

Genes hypermethylated in medulloblastomas encode proteins that play a role in a diverse range of functions, including roles in cell cycle control (TP53, TP73, RB1, p14 ${ }^{A R F}$, and $\left.p 16^{I N K 4 A}\right)$, microtubule stabilization and the regulation of mitosis (RASSF1A), regulation of transcription (HIC1), apoptosis (CASP8, DAPK), cell adhesion (CDH1), regulation of the extracellular matrix (TIMP3), DNA repair $(M G M T)$, and response to chemotherapeutic agents (MCJ). Although RASSF1A, CASP8, and HIC1 represent the most frequently epigenetically inactivated genes in medulloblastoma, and are strong candidates for tumor suppressor genes in its pathogenesis, none of these genes has been investigated in detail at the functional level in this disease. Nonetheless, studies in other tumor types are beginning to shed light on the potential mechanism(s) whereby loss of these genes may contribute to tumorigenesis at the genetic and functional levels.

RASSF1A. The RASSF1A gene is located at $3 \mathrm{p} 21.3$ and was originally identified as a candidate tumor suppressor gene in lung cancer, where it is inactivated by a combination of genetic and epigenetic mechanisms, usually involving deletion of one allele and transcriptional silencing by hypermethylation of the other ${ }^{18}$ Mutations in RASSF $1 A$ are rare, although its transcriptional silencing by hypermethylation, in combination with $3 \mathrm{p} 21.3$ deletion, is commonly observed in a range of solid tumor types, including breast, renal, and nasopharyngeal carcinomas. ${ }^{1}$ Inactivation of RASSF1A can also occur in tumor types in which $3 \mathrm{p} 21.3$ deletions are not involved, and medulloblastoma provides an important example of a tumor type in which RASSF $1 A$ inactivation occurs by biallelic hypermethylation, with no involvement of genetic mutation or deletion..$^{55}$ In addition to genetic and epigenetic data consistent with the inactivation of both RASSF $1 A$ alleles in primary tumors, several independent lines of evidence support a tumor suppressor role for the RASSF1A protein. Reintroduction of RASSF 1A into RASSF1A-silenced cell lines from a range of tumor types suppresses tumor cell growth in vitro and tumor for- mation in vivo. ${ }^{10,18,20,49}$ Conversely, depletion of RASSF1A in a cell line with a functioning RASSF1A gene has been shown to accelerate mitotic progression. ${ }^{75}$ Recent publications have described a number of potential functions for RASSF1A that are consistent with multifaceted roles in tumor suppression. These include roles in microtubule stabilization, apoptosis, and cell cycle arrest mediated through both the $\mathrm{G}_{1} / \mathrm{S}$ phase and $\mathrm{G}_{2} / \mathrm{M}$ phase mitotic checkpoints. ${ }^{1}$ Finally, homozygous disruption of Rassfla in mice causes increased susceptibility to spontaneous tumors, including lung adenoma, lymphoma, and breast adenocarcinoma. ${ }^{83}$

CASP8. The CASP8 gene is located at 2q33-q34 and encodes Caspase-8, an initiator caspase (cysteine-aspartylprotease) involved in death receptor-mediated apoptosis, and apoptosis triggered by other stimuli such as exposure to chemotherapeutic agents. ${ }^{11,73}$ Apoptosis (programmed cell death) is a crucial regulator of tissue homeostasis, and the abrogation of apoptotic pathways is a frequent event in tumor development. ${ }^{41}$ A significant proportion of medulloblastomas shows evidence of complete methylation of CASP 8,53 although genetic loss of the $2 \mathrm{q} 33$-q 34 region is rare, suggesting a primary role for epigenetic mechanisms in its inactivation in medulloblastoma. The CASP 8 gene thus represents a candidate medulloblastoma tumor suppressor gene, and inactivation of CASP 8 by $\mathrm{CpG}$ island methylation may play a role in abrogation of apoptotic pathways during medulloblastoma development. Nevertheless, little mechanistic evidence currently exists to substantiate any such functional roles in this disease.

HICl. The $\mathrm{HICl}$ gene is located at $17 \mathrm{p} 13.3$, a region frequently deleted in human cancer. Abnormalities of chromosome 17 are the ones most commonly observed in cytogenetic studies of medulloblastoma. ${ }^{26}$ Overall, losses of $17 \mathrm{p}$ are observed in 30 to $50 \%$ of cases, and frequently encompass a common region of deletion at 17p13.3, implicating the probable location of a medulloblastoma tumor suppressor gene at this locus. Although the situation is complicated by the level of background methylation observed for $\mathrm{HICl}$ in the normal cerebellum (see previous sections), complete methylation of $\mathrm{HICl}$ is observed in a significant number of medulloblastomas. The $\mathrm{HICl}$ gene is hypermethylated and transcriptionally silent in several other types of human cancer (for example, breast cancer, cervical cancer, and retinoblastoma $\left.{ }^{58,59,64,68}\right)$ and, although mutations in $H I C$ are very rare, ${ }^{88}$ its inactivation appears to adhere to a classic two-hit model, arising either through biallelic epigenetic mechanisms or epigenetic mechanisms together with chromosomal deletions. ${ }^{12}$ The $\mathrm{HICl}$ gene encodes a zinc finger transcription factor that is proposed to function as a transcriptional repressor. ${ }^{19}$ The consensus binding sequence for $\mathrm{HICl}$ has been established, but no specific target genes have yet been identified. ${ }^{66}$ Mice with one disrupted copy of Hicl develop a range of malignant tumors, including a predominance of epithelial cancers in males and lymphomas and sarcomas in females..$^{13}$ Further work has shown that the spectrum of tumors that develop in mice is influenced by the loss of other tumor suppressor genes; heterozygous disruption of $\mathrm{Hicl}$ and p53 cooperate to cause predisposition to breast and ovarian carcinomas and metastatic osteosarcomas, with epigenetic inactivation of the wild-type Hicl allele also observed in these tumors, consistent with a tumor suppressor role and two-hit inac- 
tivation. ${ }^{12}$ Accumulated genetic, epigenetic, and functional evidence thus implicates $\mathrm{HICl}$ as an epigenetically inactivated tumor suppressor gene, and as a strong candidate for medulloblastoma tumor suppressor gene at $17 \mathrm{p} 13.3$. Further investigations are now required to clarify the relative contributions of normal tissue-specific methylation, de novo methylation, and $17 \mathrm{p}$ deletion to $\mathrm{HICl}$ loss in medulloblastoma, and also to clarify any functional role it may play in medulloblastoma pathogenesis.

\section{Mechanisms of Tumor Suppressor Gene Inactivation: Implications for Gene Discovery Strategies in Medulloblastoma}

Knudson's ${ }^{48}$ two-hit model of tumor suppressor gene inactivation states that both copies of a tumor suppressor gene should be inactivated to promote tumor development, with evidence of inactivation by genetic mutation (usually nonsense or truncating mutations) considered the hallmark of a tumor suppressor gene..$^{35}$ Nevertheless, studies conducted in multiple tumor types highlight a new generation of tumor suppressor genes that redefine Knudson's hypothesis to include epigenetic inactivation as one or both of the two hits required for tumor suppressor gene inactivation. ${ }^{61}$

Data for candidate tumor suppressor genes investigated in medulloblastoma appear consistent with this revised hypothesis. Studies indicate that genetic and epigenetic events can work either in combination or in isolation to inactivate tumor suppressor genes in this disease. Of the methylated genes reported in medulloblastoma, $p 16^{I N K A A}$ is also homozygously deleted in a small percentage (10-15\%) of cases. ${ }^{4}$ Similarly, $\mathrm{HICl}$ is frequently methylated and is located at $17 \mathrm{p} 13.3$ (a common region of deletion in medulloblastoma), although $\mathrm{HICl}$ coding mutations are rare, ${ }^{72,88}$ suggesting that both genetic and epigenetic events contribute to the inactivation of these two genes in medulloblastoma. Nevertheless, the involvement of RASSF1A and CASP 8 in medulloblastoma development was not suspected prior to epigenetic studies, because neither gene is located in a chromosomal region exhibiting frequent loss in tumors. Indeed, loss of RASSF1A occurs entirely by biallelic methylation in medulloblastoma, with no involvement of genetic mutations or deletion..$^{55}$ Therefore, epigenetic studies have the power to implicate genes involved in medulloblastoma pathogenesis that are not identified in genetic studies. The role of promoter hypermethylation in the inactivation of tumor suppressor genes that are mutated in medulloblastoma is less clear. Only a limited number of these genes has been investigated epigenetically; methylation of $p 14^{A R F}$ has been reported as well as its homozygous deletion in other cases, ${ }^{28,53}$ but methylation is not commonly observed for the TP53 or APC tumor suppressor genes, ${ }^{34,36}$ suggesting that these genes are inactivated solely by genetic mechanisms. The contribution of epigenetic events to the inactivation of other mutated medulloblastoma tumor suppressor genes (for example, PTCH, SUFU, and AXINI) has not been investigated.

Candidate approaches to the identification of epigenetically inactivated genes have been successful in identifying gene-specific events associated with the development of a significant proportion of medulloblastoma cases, and strongly suggest the involvement of further hypermethylated genes. Nevertheless, only a modest number of genes have been analyzed so far for evidence of methylation in this way, and such potential approaches are by definition limited. More expansive genome-wide approaches must now be considered to aid the identification of additional epigenetically regulated genes in medulloblastoma. Such approaches include RLGS (discussed earlier), or the use of expression arrays to identify methylation-dependent candidate tumor suppressor genes, which are upregulated following demethylation treatments or inhibition of histone deacetylases. ${ }^{80,89}$ Similarly, $\mathrm{CpG}$ island arrays have been developed that allow the investigation of changes in the methylation status of thousands of $\mathrm{CpG}$ islands in a single experiment. ${ }^{90}$

Finally, the recent elucidation of additional epigenetic events that may contribute to tumor development provides important precedents that merit investigation to establish any role(s) in medulloblastoma. These include gene-specific hypomethylation events such as loss of methylation (or imprinting) of normally somatically methylated (or imprinted) growth-promoting genes, which could lead to the activation of normally silent alleles and a growth advantage (for example, S100A4 in colorectal cancer or IGF2 in multiple cancer types). ${ }^{16,57,67,84}$ Moreover, micro-RNAs are a recently discovered family of short nonprotein-coding RNA species that negatively epigenetically regulate the expression of genes involved in the control of development, proliferation, and apoptosis, and whose aberrant expression appears to contribute to cancer initiation and progression. ${ }^{15}$

\section{Prognostic and Therapeutic Potential}

The exploitation of molecular characteristics of the disease for diagnostic and therapeutic benefit offers significant promise for improving the outlook for patients with medulloblastoma. A number of the genetic features detected in medulloblastomas show significant associations with pathological features of the disease (for example, $M Y C$ or $M Y C N$ amplification and the large cell/anaplastic pathological subtype, ${ }^{21,50}$ and independent markers of both favorable (CTNNB1 status) and adverse (loss of chromosome $17 \mathrm{p}$, MYC/MYCN amplification) prognoses based on cohorts studied in clinical trials have been reported. ${ }^{27,50}$ Of the most frequently methylated genes identified in medulloblastoma, HICl methylation levels in excess of those observed in the normal brain have been reported to be independently predictive of poor overall survival. ${ }^{72}$ Similarly, tumor-specific methylation of CASP8 appears to be specific to medulloblastomas with classic and large cell/anaplastic histopathological features, and weak or low expression of the CASP8 protein in medulloblastomas has been reported as an independent indicator of poor survival. ${ }^{53,65}$ In contrast, RASSF1A hypermethylation occurs in the majority of medulloblastomas ( 90\%) and describes tumors of all clinical and histological subtypes; it thus lacks real potential as a correlate of differential clinicopathological behavior. ${ }^{53,55}$

Initial data therefore suggest that the investigation of epigenetic events could help identify markers of differential clinicopathological disease behavior in medulloblastoma for use in refined diagnostic and prognostic schemes. Along with the identification of additional markers for evaluation, the next phase in the development of these markers should therefore involve confirmatory studies, followed by prospective testing in large, uniformly treated cohorts of pa- 
tients. Other molecular, clinical, and pathological indices should also be evaluated to establish any applications as independent markers for use in routine practice.

The discovery of epigenetically inactivated genes in medulloblastoma raises the possibility of new therapies for this tumor. Unlike genetic inactivation, methylation-mediated transcriptional silencing is reversible by demethylating agents such as 5-AzaCdR, which is used clinically in the treatment of myelodysplasia and acute leukemia and has become the first drug to be approved by the US Food and Drug Administration for the treatment of myelodysplastic syndromes. ${ }^{42,52}$ Histone deacetylase inhibitors such as trichostatin A are also currently being investigated in clinical trials. ${ }^{87}$ Conceivably, treatment with demethylating agents could reactivate epigenetically silenced tumor suppressor genes involved in processes such as mitosis and the cell cycle (such as RASSF1A, TP53, p14ARF, and p16 $6^{I N K A}$ ) and slow down tumor growth. Similarly, the reactivation of genes such as CASP8, DAPK, and MCJ may sensitize tumors to other chemotherapeutic agents. ${ }^{82}$ Nevertheless, demethylating agents and histone deacetylase inhibitors lack specificity and have the potential to reactivate a wide range of epigenetically silenced genes, including both normally methylated and tumor-specific genes. In recent array-based experiments, treatment of cancer cells with demethylating agents and histone deacetylase inhibitors resulted in the methylation-dependent deregulation of hundreds of genes, including those predicted to be both growth promoting and growth inhibitory. ${ }^{80,89}$ It therefore seems unlikely that demethylating drugs or histone deacetylase inhibitors act through the targeted reactivation of cancer-specific genes, but more likely promote cell death through mechanisms that include the widespread deregulated expression of multiple gene transcripts.

Gene-specific epigenetic events detected in medulloblastoma also merit exploration as potential therapeutic targets. Our current understanding of the normal cellular functions of the major epigenetically inactivated genes (RASSF1A, $H I C 1$, and CASP8) and the consequences of their disruption in tumor development varies greatly among genes (see previous sections). The specific restoration of tumor suppressor gene function does not seem realistic. Nevertheless, given their extensive hypermethylation in medulloblastoma and major adult tumor types, along with a growing understanding of their biological roles, HICI and RASSF1A-dependent functional pathways could represent potential future targets for exploitation in cancer, once the dependence of tumor growth on their inactivation has been established.

\section{CONCLUSIONS}

Over the last decade, the identification of genes disrupted by genetic mutation in medulloblastoma has provided critical insight into the molecular pathways underlying its pathogenesis; however identification of a molecular basis for the majority of medulloblastomas remains elusive. Recent reports describing gene-specific epigenetic events in these tumors have begun to further expand and inform our understanding of this disease, and of the genes disrupted in its development. Among these, RASSFIA, CASP8, and HICl have all been identified as candidate tumor suppressor genes that are epigenetically inactivated by hyperme- thylation and transcriptional silencing in a large proportion of cases. Indeed, these represent the most common genespecific events identified to date in medulloblastoma. These events display apparent tumor specificity, although the identification of normal somatic methylation events in the normal nonneoplastic cerebellum highlights the requirement for appropriate comparative controls in methylation studies and investigations of the origins of methylation in tumors and their relationship to histogenesis of the disease. Concordant with tumor-specific roles, data from other tumor systems are consistent with tumor-suppressive functions for the RASSF $1 A$ and HICl protein products, and initial clinical studies support a role for epigenetic events as markers of differential clinical and pathological disease behavior in medulloblastoma.

Epigenetic events represent common molecular features of medulloblastoma. Their investigation has provided significant new insight into the molecular basis of this disease, and has led to the identification of genes that may play an important role in its pathogenesis. Nevertheless, our current understanding of the epigenetic basis of medulloblastoma is limited to the examination of a modest series of candidate genes. Based on current precedents, additional epigenetically regulated genes are likely to exist in medulloblastoma. More expansive genome-wide investigations are now required to identify these, and to establish with more certainty the functional roles and contributions of epigenetic events to medulloblastoma development, along with assessments of the clinicopathological relevance and potential for therapeutic exploitation of these events.

\section{Acknowledgment}

We thank Prof. David Ellison for providing critical comments on this manuscript.

\section{References}

1. Agathanggelou A, Cooper WN, Latif F: Role of the Ras-association domain family 1 tumor suppressor gene in human cancers. Cancer Res 65:3497-3508, 2005

2. Antequera F, Bird A: Number of CpG islands and genes in human and mouse. Proc Natl Acad Sci U S A 90:11995-11999, 1993

3. Aranyi T, Faucheux BA, Khalfallah O, et al: The tissue-specific methylation of the human Tyrosine Hydroxylase gene reveals new regulatory elements in the first exon. $\mathbf{J}$ Neurochem 94: 129-139, 2005

4. Barker FG, Chen P, Furman F, et al: P16 deletion and mutation analysis in human brain tumors. J Neurooncol 31:17-23, 1997

5. Bartolomei MS, Tilghman SM: Genomic imprinting in mammals. Annu Rev Genet 31:493-525, 1997

6. Baylin SB, Esteller M, Rountree MR, et al: Aberrant patterns of DNA methylation, chromatin formation and gene expression in cancer. Hum Mol Genet 10:687-692, 2001

7. Bestor TH: The DNA methyltransferases of mammals. Hum Mol Genet 9:2395-2402, 2000

8. Bienz-Tadmor B, Zakut-Houri R, Libresco S, et al: The 5' region of the p53 gene: evolutionary conservation and evidence for a negative regulatory element. EMBO J 4:3209-3213, 1985

9. Bird A: DNA methylation patterns and epigenetic memory. Genes Dev 16:6-21, 2002

10. Burbee DG, Forgacs E, Zochbauer-Muller S, et al: Epigenetic inactivation of RASSF1A in lung and breast cancers and malignant phenotype suppression. J Natl Cancer Inst 93:691-699, 2001 
11. Chen M, Wang J: Initiator caspases in apoptosis signaling pathways. Apoptosis 7:313-319, 2002

12. Chen W, Cooper TK, Zahnow CA, et al: Epigenetic and genetic loss of Hicl function accentuates the role of p53 in tumorigenesis. Cancer Cell 6:387-398, 2004

13. Chen WY, Zeng X, Carter MG, et al: Heterozygous disruption of Hicl predisposes mice to a gender-dependent spectrum of malignant tumors. Nat Genet 33:197-202, 2003

14. Costello JF, Fruhwald MC, Smiraglia DJ, et al: Aberrant CpGisland methylation has non-random and tumor-type-specific patterns. Nat Genet 24:132-138, 2000

15. Croce CM, Calin GA: miRNAs, cancer, and stem cell division. Cell 122:6-7, 2005

16. Cui H, Horon IL, Ohlsson R, et al: Loss of imprinting in normal tissue of colorectal cancer patients with microsatellite instability. Nat Med 4:1276-1280, 1998

17. Dahl C, Guldberg P: DNA methylation analysis techniques. Biogerontology 4:233-250, 2003

18. Dammann R, Li C, Yoon JH, et al: Epigenetic inactivation of a RAS association domain family protein from the lung tumour suppressor locus 3p21.3. Nat Genet 25:315-319, 2000

19. Deltour S, Pinte S, Guerardel C, et al: The human candidate tumor suppressor gene $\mathrm{HICl}$ recruits $\mathrm{CtBP}$ through a degenerate GLDLSKK motif. Mol Cell Biol 22:4890-4901, 2002

20. Dreijerink K, Braga E, Kuzmin I, et al: The candidate tumor suppressor gene, RASSF1A, from human chromosome 3p21.3 is involved in kidney tumorigenesis. Proc Natl Acad Sci U S A 98:7504-7509, 2001

21. Eberhart CG, Kratz JE, Schuster A, et al: Comparative genomic hybridization detects an increased number of chromosomal alterations in large cell/anaplastic medulloblastomas. Brain Pathol 12:36-44, 2002

22. Ebinger M, Senf L, Wachowski O, et al: Promoter methylation pattern of caspase-8, P16 ${ }^{\mathrm{INK} 4 \mathrm{~A}}$, MGMT, TIMP-3, and E-cadherin in medulloblastoma. Pathol Oncol Res 10:17-21, 2004

23. Egger G, Liang G, Aparicio A, et al: Epigenetics in human disease and prospects for epigenetic therapy. Nature 429: 457-463, 2004

24. Ehrlich M: DNA methylation in cancer: too much, but also too little. Oncogene 21:5400-5413, 2002

25. Ellison D: Classifying the medulloblastoma: insights from morphology and molecular genetics. Neuropathol Appl Neurobiol 28:257-282, 2002

26. Ellison DW, Clifford SC, Gajjar A, et al: What's new in neurooncology? Recent advances in medulloblastoma. Eur J Paediatr Neurol 7:53-66, 2003

27. Ellison DW, Onilude OE, Lindsey JC, et al: $\beta$-catenin status predicts a favorable outcome in childhood medulloblastoma: the United Kingdom Children's Cancer Study Group Brain Tumour Committee. J Clin Oncol 23:7951-7957, 2005

28. Frank AJ, Hernan R, Hollander A, et al: The TP53-aRF tumor suppressor pathway is frequently disrupted in large/cell anaplastic medulloblastoma. Brain Res Mol Brain Res 121: 137-140, 2004

29. Fruhwald MC, O'Dorisio MS, Dai Z, et al: Aberrant promoter methylation of previously unidentified target genes is a common abnormality in medulloblastomas-implications for tumor biology and potential clinical utility. Oncogene 20:5033-5042, 2001

30. Futscher BW, Oshiro MM, Wozniak RJ, et al: Role for DNA methylation in the control of cell type specific maspin expression. Nat Genet 31:175-179, 2002

31. Gardiner-Garden M, Frommer M: CpG islands in vertebrate genomes. J Mol Biol 196:261-282, 1987

32. Giangaspero F, Bigner SH, Kleihues P, et al: Medulloblastoma, in Kleihues P, Cavanee WK (eds): World Health Organization Classification of Tumors. Pathology and GeneticsTumours of the Nervous System. Lyon: IARC, 2000, pp 129-137
33. Gonzalez-Gomez P, Bello MJ, Inda MM, et al: Deletion and aberrant $\mathrm{CpG}$ island methylation of Caspase 8 gene in medulloblastoma. Oncol Rep 12:663-666, 2004

34. Gonzalez-Gomez P, Bello MJ, Lomas J, et al: Epigenetic changes in pilocytic astrocytomas and medulloblastomas. Int J Mol Med 11:655-660, 2003

35. Hanahan D, Weinberg RA: The hallmarks of cancer. Cell 100: 57-70, 2000

36. Harada K, Toyooka S, Maitra A, et al: Aberrant promoter methylation and silencing of the RASSF1A gene in pediatric tumors and cell lines. Oncogene 21:4345-4349, 2002

37. Harada K, Toyooka S, Shivapurkar N, et al: Deregulation of caspase 8 and 10 expression in pediatric tumors and cell lines. Cancer Res 62:5897-5901, 2002

38. Heard E, Clerc P, Avner P: X-chromosome inactivation in mammals. Annu Rev Genet 31:571-610, 1997

39. Herman JG, Baylin SB: Gene silencing in cancer in association with promoter hypermethylation. N Engl J Med 349: 2042-2054, 2003

40. Horiguchi K, Tomizawa Y, Tosaka M, et al: Epigenetic inactivation of RASSF1A candidate tumor suppressor gene at $3 \mathrm{p} 21.3$ in brain tumors. Oncogene 22:7862-7865, 2003

41. Igney FH, Krammer PH: Death and anti-death: tumor resistance to apoptosis. Nat Rev Cancer 2:277-288, 2002

42. Issa JP, Kantarjian H: Azacitidine. Nat Rev Drug Discov Suppl:S6-S7, 2005

43. Jones PA: Altering gene expression with 5-azacytidine. Cell 40: 485-486, 1985

44. Jones PA: The DNA methylation paradox. Trends Genet 15: 34-37, 1999

45. Jones PA, Baylin SB: The fundamental role of epigenetic events in cancer. Nat Rev Genet 3:415-428, 2002

46. Jones PA, Laird PW: Cancer epigenetics comes of age. Nat Genet 21:163-167, 1999

47. Jones PA, Wolkowicz MJ, Rideout WM III, et al: De novo methylation of the MyoDl CpG island during the establishment of immortal cell lines. Proc Natl Acad Sci U S A 87: 6117-6121, 1990

48. Knudson AG Jr: Mutation and cancer: statistical study of retinoblastoma. Proc Natl Acad Sci U S A 68:820-823, 1971

49. Kuzmin I, Gillespie JW, Protopopov A, et al: The RASSF1A tumor suppressor gene is inactivated in prostate tumors and suppresses growth of prostate carcinoma cells. Cancer Res 62: 3498-3502, 2002

50. Lamont JM, McManamy CS, Pearson AD, et al: Combined histopathological and molecular cytogenetic stratification of medulloblastoma patients. Clin Cancer Res 10:5482-5493, 2004

51. Langdon JA, Lamont JM, Scott DK, et al: Combined genomewide allelotyping and copy number analysis identify frequent genetic losses without copy number reduction in medulloblastoma. Genes Chromosomes Cancer 45:47-60, 2005

52. Leone G, Teofili L, Voso MT, et al: DNA methylation and demethylating drugs in myelodysplastic syndromes and secondary leukemias. Haematologica 87:1324-1341, 2002

53. Lindsey JC, Lusher ME, Anderton JA, et al: Identification of tumor-specific epigenetic events in medulloblastoma development by hypermethylation profiling. Carcinogenesis 25: 661-668, 2004

54. Lindsey JC, Lusher ME, Strathdee G, et al: Epigenetic inactivation of $M C J$ (DNAJD1) in malignant paediatric brain tumours. Int J Cancer: Epub ahead of print 27 Jul, 2005

55. Lusher ME, Lindsey JC, Latif F, et al: Biallelic epigenetic inactivation of the RASSF1A tumor suppressor gene in medulloblastoma development. Cancer Res 62:5906-5911, 2002

56. Morgan HD, Santos F, Green K, et al: Epigenetic reprogramming in mammals. Hum Mol Genet 14 Spec No 1:R47-R58, 2005

57. Nakamura N, Takenaga K: Hypomethylation of the metastasis-associated S100A4 gene correlates gene activation in human colon adenocarcinoma cell lines. Clin Exp Metastasis 16: 471-479, 1998 
58. Narayan $\mathrm{G}$, Arias-Pulido $\mathrm{H}$, Koul $\mathrm{S}$, et al: Frequent promoter methylation of $C D H 1, D A P K, R A R B$, and $H I C l$ genes in carcinoma of cervix uteri: its relationship to clinical outcome. Mol Cancer 2:24, 2003

59. Nicoll G, Crichton DN, McDowell HE, et al: Expression of the Hypermethylated in cancer gene $(H I C-l)$ is associated with good outcome in human breast cancer. Br J Cancer 85: 1878-1882, 2001

60. Ohtani-Fujita N, Fujita T, Aoike A, et al: CpG methylation inactivates the promoter activity of the human retinoblastoma tumor-suppressor gene. Oncogene 8:1063-1067, 1993

61. Paige AJ: Redefining tumor suppressor genes: exceptions to the two-hit hypothesis. Cell Mol Life Sci 60:2147-2163, 2003

62. Pang JC, Chang Q, Chung YF, et al: Epigenetic inactivation of DLC-1 in supratentorial primitive neuroectodermal tumor. Hum Pathol 36:36-43, 2005

63. Pantoja C, de Los Rios L, Matheu A, et al: Inactivation of imprinted genes induced by cellular stress and tumorigenesis. Cancer Res 65:26-33, 2005

64. Parrella P, Scintu M, Prencipe M, et al: HIC1 promoter methylation and $17 \mathrm{p} 13.3$ allelic loss in invasive ductal carcinoma of the breast. Cancer Lett 222:75-81, 2005

65. Pingoud-Meier C, Lang D, Janss AJ, et al: Loss of caspase8 protein expression correlates with unfavorable survival outcome in childhood medulloblastoma. Clin Cancer Res 9: 6401-6409, 2003

66. Pinte S, Stankovic-Valentin N, Deltour S, et al: The tumor suppressor gene HICl (hypermethylated in cancer 1) is a sequencespecific transcriptional repressor: definition of its consensus binding sequence and analysis of its DNA binding and repressive properties. J Biol Chem 279:38313-38324, 2004

67. Rainier S, Johnson LA, Dobry CJ, et al: Relaxation of imprinted genes in human cancer. Nature 362:747-749, 1993

68. Rathi A, Virmani AK, Harada K, et al: Aberrant methylation of the HIC1 promoter is a frequent event in specific pediatric neoplasms. Clin Cancer Res 9:3674-3678, 2003

69. Richardson B: Impact of aging on DNA methylation. Ageing Res Rev 2:245-261, 2003

70. Robertson KD: DNA methylation and human disease. Nat Rev Genet 6:597-610, 2005

71. Rood BR, Zhang H, Cogen PH: Intercellular heterogeneity of expression of the MGMT DNA repair gene in pediatric medulloblastoma. Neuro-oncol 6:200-207, 2004

72. Rood BR, Zhang H, Weitman DM, et al: Hypermethylation of HIC-1 and 17p allelic loss in medulloblastoma. Cancer Res 62: 3794-3797, 2002

73. Salvesen GS: Caspases and apoptosis. Essays Biochem 38: 9-19, 2002

74. Schroeder M, Mass MJ: CpG methylation inactivates the transcriptional activity of the promoter of the human p53 tumor suppressor gene. Biochem Biophys Res Commun 235: 403-406, 1997

75. Song MS, Song SJ, Ayad NG, et al: The tumor suppressor RASSF1A regulates mitosis by inhibiting the APC-Cdc20 complex. Nat Cell Biol 6:129-137, 2004

76. Spencer VA, Sun JM, Li L, et al: Chromatin immunoprecipitation: a tool for studying histone acetylation and transcription factor binding. Methods 31:67-75, 2003

77. Stirzaker C, Song JZ, Davidson B, et al: Transcriptional gene silencing promotes DNA hypermethylation through a sequential change in chromatin modifications in cancer cells. Cancer Res 64:3871-3877, 2004
78. Strathdee G, Davies BR, Vass JK, et al: Cell type-specific methylation of an intronic $\mathrm{CpG}$ island controls expression of the MCJ gene. Carcinogenesis 25:693-701, 2004

79. Strathdee G, Sim A, Brown R: Control of gene expression by $\mathrm{CpG}$ island methylation in normal cells. Biochem Soc Trans 32:913-915, 2004

80. Suzuki H, Gabrielson E, Chen W, et al: A genomic screen for genes upregulated by demethylation and histone deacetylase inhibition in human colorectal cancer. Nat Genet 31:141-149, 2002

81. Taipale J, Beachy PA: The Hedgehog and Wnt signalling pathways in cancer. Nature 411:349-354, 2001

82. Teodoridis JM, Strathdee G, Brown R: Epigenetic silencing mediated by $\mathrm{CpG}$ island methylation: potential as a therapeutic target and as a biomarker. Drug Resist Updat 7:267-278, 2004

83. Tommasi S, Dammann R, Zhang Z, et al: Tumor susceptibility of Rassfla knockout mice. Cancer Res 65:92-98, 2005

84. Ulaner GA, $\mathrm{Vu} \mathrm{TH,} \mathrm{Li} \mathrm{T,} \mathrm{et} \mathrm{al:} \mathrm{Loss} \mathrm{of} \mathrm{imprinting} \mathrm{of} \mathrm{IGF2} \mathrm{and}$ H19 in osteosarcoma is accompanied by reciprocal methylation changes of a CTCF-binding site. Hum Mol Genet 12:535-549, 2003

85. Ushijima T, Okochi-Takada E: Aberrant methylations in cancer cells: where do they come from? Cancer Sci 96:206-211, 2005

86. van Rijnsoever M, Grieu F, Elsaleh H, et al: Characterisation of colorectal cancers showing hypermethylation at multiple $\mathrm{CpG}$ islands. Gut 51:797-802, 2002

87. Vigushin DM, Coombes RC: Targeted histone deacetylase inhibition for cancer therapy. Curr Cancer Drug Targets 4: 205-218, 2004

88. Waha A, Waha A, Koch A, et al: Epigenetic silencing of the HIC-1 gene in human medulloblastomas. J Neuropathol Exp Neurol 62:1192-1201, 2003

89. Yamashita K, Upadhyay S, Osada M, et al: Pharmacologic unmasking of epigenetically silenced tumor suppressor genes in esophageal squamous cell carcinoma. Cancer Cell 2:485-495, 2002

90. Yan PS, Perry MR, Laux DE, et al: CpG island arrays: an application toward deciphering epigenetic signatures of breast cancer. Clin Cancer Res 6:1432-1438, 2000

91. Yoder JA, Walsh CP, Bestor TH: Cytosine methylation and the ecology of intragenomic parasites. Trends Genet 13:335-340, 1997

92. Zendman AJ, Ruiter DJ, Van Muijen GN: Cancer/testis-associated genes: identification, expression profile, and putative function. J Cell Physiol 194:272-288, 2003

93. Zuzak TJ, Steinhoff DF, Sutton LN, et al: Loss of caspase8 mRNA expression is common in childhood primitive neuroectodermal brain tumor/medulloblastoma. Eur J Cancer 38: 83-91, 2002

Manuscript received October 13, 2005.

Accepted in final form November 7, 2005.

This study has been funded by the North of England Children's Cancer Research Fund (NECCRF), the Samantha Dickson Research Trust (SDRT), Charlie's Challenge, and The Katie Trust and Cancer Research UK (CR-UK).

Address reprint requests to: Steven C. Clifford, Ph.D., Northern Institute for Cancer Research, University of Newcastle, The Medical School, Framlington Place, Newcastle upon Tyne, NE2 4HH, United Kingdom. email: s.c.clifford@ncl.ac.uk. 